\title{
La otra prédica: la huelga de la Universidad de París (1229-31) como 'escuela de guerra' del intelectual del sistema ${ }^{1}$
}

\author{
The other sermon: the strike of the University of Paris (1229-31) as a 'school of war' of the intellectual of the system
}

\author{
Damian Andres Rivas \\ Facultad de Filosofia y Letras, Universidad de Buenos Aires, Argentina \\ damianandresrivas@gmail.com
}

\begin{abstract}
Resumen:
A partir del estudio de sermones de miembros de la Iglesia, predicados durante la huelga de la Universidad de París (1229-31), se analizan las formas en que los distintos segmentos eclesiásticos intervinieron contra la corporación que buscaba su autonomía. Construyeron su prédica para interpelar al público escolar que no había abandonado la ciudad. Esto permite abordar, por un lado, los objetivos de la Iglesia para dominar la universidad y sus modelos educativos; por el otro, la reacción que desplegó frente a la corporación como contra los movimientos comunales, en un marco de conflictos que buscaban encuadrar los espacios urbanos en el feudalismo. Se caracteriza el rol de los estudios en el programa político de la Iglesia reformada para la creación de nuevos cuadros que encabezaron aquella regimentación, donde surgió un nuevo actor clave: las órdenes mendicantes. A partir del análisis crítico de la interpretación liberal de las revueltas, representada por José Luis Romero, se reflexiona sobre el lugar que ocupó la lucha de los escolares parisinos en el marco de los conflictos urbanos para pensar el rol de la Iglesia en el proceso de ampliación del poder feudal. Palabras ClaVe: Huelga universitaria, Universidad de Paris, Intelectual del sistema, Revolución burguesa, José Luis Romero.
\end{abstract}

\section{Abstract:}

The study of sermons from different clergymen, preached during the strike of the University of Paris (1229-31), enables us to analyze the ways in which the Church intervened against the corporation that struggled for autonomy. The sermons were elaborated to appeal the scholars that remained in the city. Thus, two issues are examined: on one hand, the aims of the Church to dominate the university and its academic life; on the other, the reaction deployed against both, the corporative movement as well as the communal movements around Europe, looking to frame the emerging feudal cities. The studium is approached to understand its role in the political programme of the reformed Church for the creation of new agents that leaded the regimentation, giving way to the emergence of key actors: the mendicant orders. Critically taking into consideration the liberal approach on bourgeois revolutions, that of José Luis Romero, looking at the relationship between the struggle of the university and the urban conflicts in general allows us to characterize the role of the Church in the process of expansion of feudalism (XI-XIII century).

KEYWORDS: University strike, University of Paris, Intellectuals of the system, Bourgeois revolution, José Luis Romero.

Una primera pregunta que surge del análisis de los conflictos que protagonizaron los escolares parisinos y culminó con la gran huelga de 1229-31 es la relación existente entre este proceso y las llamadas "revoluciones burguesas". Los enfrentamientos urbanos y el conflicto con el poder episcopal, el juego de alianzas con la monarquía y el papado, el desarrollo de formas creativas de lucha, entre otros, son algunos de los elementos que permiten pensar este conflicto dentro de un marco mayor donde se disputaba la dominación de las nuevas formas de vida social: las ciudades que "renacían" con la expansión feudal a partir del siglo XI. Sin embargo se presenta también una primera diferencia sustantiva: la huelga universitaria tuvo como objetivo consolidar la autonomía corporativa de los intelectuales y no obtener el control político de la ciudad, como sí lo hicieron numerosas rebeliones en el norte de Italia, en el reino castellano, en Flandes, etc., entre los siglos XI y XIII. Se abordarán, entonces, las similitudes y diferencias entre el caso parisino y la dinámica general de las luchas 
urbanas de los siglos de expansión, la “revolución burguesa” que estudió José Luis Romero, para caracterizar la singularidad del conflicto y sus formas contestatarias en un marco mayor de lucha, así como para repensar este clásico tópico historiográfico desde un caso singular.

En este contexto, la activa participación de distintos sectores de la Iglesia para dirigir los conflictos y dominar las nuevas formas y espacios de vida social permite pensar una segunda instancia problemática: las razones, los objetivos y las formas de la lucha de la Iglesia, la relación de la institución con la educación de sus miembros y las recientemente creadas universidades, los intereses diferenciados de distintos segmentos del estamento eclesiástico y la relación entre ellos y otros sectores de la clase dominante feudal, el rol de la predicación y el aporte subjetivo de los dirigentes tanto al desarrollo como al resultado de la lucha. A partir del estudio de sermones que predicaron distintos miembros de la Iglesia en la fase de la dispersión de la huelga parisina (1229-31) se analizará el interés de la jerarquía eclesiástica en las luchas urbanas en general y en la lucha de la organización de la corporación universitaria en particular, por la importancia que le dieron a la educación y la formación de nuevos cuadros dirigentes de la Iglesia reformada. La huelga de la Universidad de París, momento en el cual las órdenes mendicantes lograron entrar a la corporación y -posteriormentedominarla, puede pensarse como "escuela de guerra" de la Iglesia en su lucha por dominar las ciudades.

\section{1) Los conflictos en la Universidad de París y "LA revolución burguesa en el MUNDO FEUDAL"}

Entre los años 1200 y 1231 se desarrolló un largo proceso de lucha entre escolares parisinos y la jerarquía eclesiástica de la ciudad encabezada por el obispo, con la participación tanto del papado como de la monarquía francesa que residía en dicha ciudad, en torno al control de la vida social que desarrollaron maestros y estudiantes en la tarea común del intelectual: "el oficio de pensar y enseñar lo que piensan" (Le Goff, 1971, p. 6). El conflicto no puede ser analizado aisladamente: entre los siglos XI y XIII, el "renacimiento urbano" (Baschet, 2009, pp. 150-55) que tuvo lugar en el occidente medieval fue acompañado por una serie de movimientos sociales que lucharon por el control de su propia forma de vida, originada en ese mismo renacimiento.

La tradición liberal y uno de sus principales representantes en la historiografía local que fue José Luis Romero (1967), vio en los habitantes del burgo feudal el antecedente directo del sujeto revolucionario de los siglos XVIII y XIX que inauguraría la sociedad capitalista ${ }^{2}$. Esto condujo a caracterizar las ciudades medievales y sus luchas como elementos exógenos al feudalismo, que lo negaban, engendrando una forma social moderna, dinámica, burguesa y mercantil, opuesta a la supuesta "economía natural" del campo feudal (Romero, 1967, pp. 282-89). Una larga serie de estudiosos posteriores vio en las relaciones sociales feudales el demiurgo histórico de nuevas formas sociales a partir de su propio movimiento auto-transformador, y en la polarización entre acumuladores y proto-asalariados dentro del campesinado feudal, las condiciones de posibilidad del desarrollo de nuevas clases capitalistas (Astarita, 2012, pp. 3-6). Así también, los estudios sobre las ciudades en el feudalismo coincidieron en que estas no negaban el modo de producción feudal sino que, producto de su propio movimiento, ampliaban las formas de dominación para la reproducción de un feudalismo plenamente desarrollado (Morsel, 2008) ${ }^{3}$.

Aún con las indicadas limitaciones, el estudio de Romero sobre la "revolución burguesa" aporta un complejo esquema para pensar el ciclo general de los conflictos urbanos en los siglos de expansión, como también proporciona elementos para caracterizar la dinámica y las formas diferenciadas y cambiantes de esa lucha. La de los universitarios parisinos presenta una serie de características comunes a los movimientos comunales y permite pensar en qué medida se enmarcaron dentro de esa dinámica general del feudalismo en expansión y cómo se inscribieron y a su vez determinaron las nuevas formas de lucha que inauguraba la vida en la ciudad. Entendiendo que el caso no se trató de una "revolución burguesa" ya que no encabezaron una lucha por el control político de la ciudad sino que lucharon por la autonomía de la corporación (que 
comprende solamente el poder político y económico de esa parte de la sociedad urbana, dentro de un mayor cuadro jerárquico de poder), se puede pensar el nuevo encuadramiento de la ciudad, y de la universidad en particular, desde el aporte que hicieron a la ampliación de la sociedad feudal y la reproducción de su lazo social fundado sobre la explotación y la dominación, donde la Iglesia como estamento diferenciado de la clase dominante jugaba un rol clave.

Romero no profundiza en su estudio la dinámica de las luchas por los oficios en general ni de las universitarias en particular, pero puede aportar para pensarla a partir de las condiciones comunes de los conflictos urbanos. Las premisas generales que plantea para pensar los enfrentamientos sociales entre los siglos XI y XIII permiten ubicar el conflicto de París en ese marco: se trataba de un nuevo grupo social, el de los intelectuales, que comenzó a desarrollar de facto una nueva forma de vida en torno a su oficio (como se desplegaron otras actividades de la forma social urbana) planteando un dilema a la dominación de la clase feudal, por tratarse de nuevos elementos sociales "al margen de las condiciones vigentes" (Romero, 1967, p. 331), frente al cual ésta buscó reestructurarse. El desarrollo de las escuelas catedralicias y abaciales parisinas durante el siglo XII que tan bien muestran las autobiografías de Pedro Abelardo (ed. 1854) o Guibert de Nogent (ed. 1854) ${ }^{4}$, posibilitó que a principios del siglo XIII las escuelas de Notre-Dame, Sainte-Genevive y Saint-Victor recibieran numerosos estudiantes de diversas regiones y, junto a los maestros, desarrollaran asociados una dinámica vida social en el seno de la ciudad y en torno a su oficio. Frente a este nuevo fenómeno particular dentro de la -a su vez- nueva vida urbana, reaccionó el poder episcopal para dirigirla y regimentarla (Fraboschi, 1991, p. 13): la fuerza que las había engendrado abrió posibilidades de desarrollo que escapaban a las formas de dominación existentes planteando un panorama de enfrentamientos (Romero, 1967, p. 333). Sin embargo, el conflicto con el poder episcopal estaba atravesado, como marca Romero (1967, p. 336), por una crisis religiosa al interior de la Iglesia que engendró una atmósfera favorable para la acción contestataria. La llamada "reforma eclesiástica" (Faci Lacasta, 2007, pp. 79-81) se desarrolló, entre otras cosas, como un doble movimiento de centralización del poder en torno a la jerarquía eclesiástica, con el papa como cabeza de la Iglesia, con su contracara, la consiguiente regimentación de dicho estamento que implicaba encuadrar el poder del obispo para que actuara como brazo local. Este movimiento al interior del estamento y de la institución se configuraba en conflicto con el cesaropapismo imperial, para lo cual elevaba la sede apostólica justificándola con una doctrina teocrática. Los conflictos abiertos en torno a la organización de nuevos espacios donde la dominación no se había estabilizado "ofrecía inusitadas perspectivas no solo para sus miembros sino también para todos los que se incorporaran al proceso: reyes, señores, clérigos" (Romero, 1967, p. 338), y puede agregarse al papado.

El conflicto comenzó coyunturalmente en el año 1200 con una riña entre estudiantes y vecinos que conllevó el pedido de justicia al rey por parte de los maestros, finalmente aceptado por Felipe Augusto, otorgando privilegios de inmunidad y fuero eclesiástico bajo juramento y oficializando la autonomía jurídica (Chartularium, 1991, p. 12). Aún así, el poder episcopal no cedió fácilmente y a lo largo de tres décadas la disputa tomó diversos rumbos. La administración académica estaba en manos del obispo, quien en 1210 prohibió bajo pena de excomunión la lectura de ciertos autores y libros para el estudio, entre ellos los escritos de Aristóteles (Chartularium, 1991, p. 14), apoyándose en la Facultad de Teología y en su autoridad en cuestiones de la fe contra la Facultad de Artes, donde comenzaba a extenderse la dialéctica y el conocimiento a través de la razón (Fraboschi, 1991, p. 15). Evidentemente, la Iglesia no quería en París cualquier universidad sino una que profundizara los fundamentos de su posición dominante, y en el impulso a una Facultad de Teología ponderaron la autoridad que otorgaban las Escrituras para la formación de predicadores. París aparecía como un posible punto de apoyo para Roma y su formación de intelectuales eclesiásticos, frente a las universidades del Imperio donde tuvo un importante lugar el estudio de los autores profanos antiguos, ligados a las necesidades y a la convivencia que imponía ese poder regional (Le Goff, 1983, pp. 190-1 y 193-4). Inocencio III apoyó el control más estricto del obispo de París sobre los profesores de teología pero a la vez permitió que fueran los maestros quienes eligieran un colega para ser nombrado canciller, que era el 
encargado de otorgar la licentia docendi. Las posiciones no estaban claras, variaban de acuerdo a los intereses profundos como con las perspectivas que otorgaba el oportunismo. "Los intelectuales se vieron obligados a elegir el camino de la dependencia eclesiástica, contrariando así la marcada corriente que los empujaba hacia el laicismo" (Le Goff, 1971, p. 97). Pero, con ese antecedente, la apelación al pontífice se volvió un recurso de los maestros y en 1215 el legado papal promulgó los estatutos que regimentaron la vida universitaria, consolidando una primera institucionalización corporativa (Fraboschi, 1991, p. 17). Así se forjaba una de las condiciones que posibilitó el desarrollo del pensamiento crítico en el seno de la autonomía corporativa bajo el amparo de las contradicciones políticas (Astarita, 2005, p. 6). Esto explica las relaciones de París con la teología, así como las ciudades del norte de Italia bajo influencia imperial con el derecho civil y los franciscanos de la corte aragonesa con el espiritualismo.

De esta forma, la dinámica del conflicto no solo atiende a cuestiones propias de la vida universitaria. En abierta contienda entre Imperio y Papado, Honorio III prohibía muy estrictamente que en París alguien se atreviera a enseñar o asistir a clases de derecho civil (Chartularium, 1991, p. 23). El papado necesitaba reforzar sus vínculos con París (donde impulsaba la teología, fundamento de su poder) y Francia en general (cuna de viejas herejías), frente a la autonomía que cobraban las ligas del norte de Italia y la dominación del sur por parte del Imperio, donde por ejemplo Federico II impulsaba la universidad de Nápoles (Claramunt, 1999, p. 208).

La disputa se verifica también al interior de la jerarquía de poderes: los maestros parisinos continuaban sus quejas contra el obispo por excomulgarlos sin reconocer el estatuto universitario, entre otras avanzadas del poder episcopal (Chartularium, 1991, p. 28). También callaba la voz de la ciencia, suspendía a maestros y mandaba a prisión a escolares que participaban en desórdenes urbanos: era una disputa por el control de ese espacio social. Frente a la excomunión que sufrieron los escolares en 1219, maestros y estudiantes tomaron medidas más drásticas: cesaron las actividades universitarias y se declararon en huelga. El papado no solo legitimó la asociación corporativa que limitaba el poder episcopal local sino que garantizó la subsistencia de los estudiantes (Chartularium, 1991, p. 23), generando un vínculo directo entre corporación y papado. Pero el nuevo papa Gregorio IX comenzó a expresar su preocupación por ciertos problemas doctrinales que renacían en París, como la utilización de la filosofía en la enseñanza de la teología, profundizando la relación de alianza-encuadramiento mediante el sometimiento de la filosofía a la palabra celestial (Chartularium, 1991, p. 29).

El punto más álgido del conflicto, que mostró el poder de las fuerzas sociales reales, tuvo lugar con la huelga que se inició en 1229. Tras incidentes en una taberna, el poder episcopal desplegó una feroz represión, a la cual respondió la corporación con la huelga y el abandono de la ciudad, hecho conocido como la Gran Dispersión (Chartularium, 1991, p. 39) ${ }^{5}$. Era un contexto particular en el cual la monarquía, que había apoyado la corporación de los intelectuales, se encontraba debilitada en tiempos de minoridad real de Luis IX bajo la regencia de su madre, Blanca de Castilla. Tanto el rey como el papa se apresuraron a confirmar los privilegios universitarios, aunque la dispersión llevó a la mayoría de estudiantes y maestros a Orleans, Toulouse y Oxford, mientras las órdenes mendicantes aprovechaban el vacío dejado para ingresar en las escuelas parisinas. El conflicto se resolvió antes de lo esperado con la bula Parens scientiarum que no solo ratificaba la autonomía jurídica, sino que también otorgaba a la corporación la capacidad de licenciar, consolidando su derecho a la huelga, a la vez que limitaba la extensión de los estudios filosóficos (Chartularium, 1991, p. 50). La jurisdicción papal chocó con la del rey, quien permitía al obispo castigar los desórdenes, mientras la predilección del primero por los universitarios llevó a arbitrar su protección y libertad con los otros poderes (Chartularium, 1991, pp. 55-56).

Varios aspectos permiten pensar este conflicto en el marco de los movimientos que caracteriza Romero. Por un lado, su origen contiene ciertos elementos comunes: un estallido coyuntural a raíz de una circunstancia cotidiana que habilitaba que tensiones más profundas afloraran a la superficie (Romero, 1967, p. 351). No fue casual que las riñas que dieron lugar al inicio del proceso conflictivo, como también a la gran huelga de 
1229, tuvieran lugar en una taberna. La vida en la ciudad conllevaba una concentración poblacional y una sociabilidad que encontraba en tabernas y posadas (muy transitadas por los universitarios) un espacio de confrontación de "ideas y costumbres, formas de pensamiento y de conducta" (Romero, 1967, pp. 404, 456) ${ }^{6}$. El conflicto en París estuvo atravesado por múltiples fuerzas y luchas de poder, pero de ninguna manera puede ser aislado de las condiciones que le dan vida: se trata de un conflicto urbano cercano a las formas de lucha que caracterizaron a las rebeliones comunales.

Se conjugaban la lucha por reducir la injerencia señorial con circunstancias derivadas del oficio y la voluntad de controlarlo, que cristalizó luego como búsqueda definida de autonomía. También apareció desde un primer momento la alianza con el poder real: el monarca vio con buenos ojos el desarrollo de la actividad en la ciudad por tratarse de una fuente de recursos, y los universitarios encontraron en el privilegio real un punto de apoyo para fortalecerse contra el obispo (Romero, 1967, p. 357). Los primeros acuerdos y la reflexión aparecieron en formas institucionalizadas con los privilegios primero y los estatutos después, dinámica común a las luchas burguesas.

La acumulación de experiencia y la obtención de resultados favorables decantaron lentamente como aprendizaje a partir de luchas parciales, y fueron constituyendo la determinación que luego estará en la base de la radicalización del movimiento. La conmoción religiosa arrastraba conmociones sociales, y la acusación de herejía e inmoralidad -que expresa la lectura de las nuevas formas de vida ante los ojos tradicionales del obispo- se sumó a la crítica a los hábitos y normas nuevas de la vida de la corporación que escapaban al control del obispo. Cuando este apeló a medidas mayores, primero castigo y represión, luego excomunión, la respuesta de los maestros también se incrementó con el cese de actividades y la huelga de toda la corporación. Cuando no encontraban respuesta en sus métodos, acelerada la coyuntura por la oposición que recibieron de la monarquía, decidieron abandonar la ciudad. Romero (1967, p. 378) describe este método como una verdadera innovación de la lucha urbana, en este caso atravesada por una coyuntura compartida con los movimientos antiseñoriales: la minoridad real como cierto vacío de un poder paternalista profundizaba el debilitamiento del lazo social y la pérdida del sentido, volviendo más factible las medidas de fuerza y habilitando paralelamente la decisión no esperable -en relación a la postura anterior de la monarquía- que tomó la reina regente.

Otro elemento que señala Romero (1967, pp. 341, 354) presente en los movimientos comunales, y que apareció en París, lleva a pensar en la cercanía de estas luchas y las razones de su radicalización, en la medida en que la excomunión consolidaba la imagen que los sujetos enfrentados tenían de su enemigo. Hay un cambio entre, por un lado, apelar a autoridades superiores para que negocien por medios pacíficos y, por el otro, la utilización de métodos que implicaban acción directa y afectaban la vida de la ciudad. Romero dice que la excomunión los llevaba "de rogar a luchar" (Romero, 1967, p. 354) expresando cómo la acción espontánea o la mera reacción fue tomando tintes más conscientes y medidas más pensadas mientras el mismo proceso contestatario se desarrollaba.

En este movimiento parisino el "grupo disidente" no estaba tan definido como sí ve Romero en las fases antiseñorial y popular del ciclo revolucionario. Si por un lado en términos de identidad política los intelectuales desarrollaban su conciencia corporativa por oposición al poder episcopal y su lucha común generaba vínculos cohesionantes, cuestión que ve Romero en las primeras luchas burguesas, por el otro aparecían elementos de su existencia que los acerca más a los movimientos populares: eran asalariados que ejercían una profesión liberal y trazaban una relación con poderes mayores que se recubrían de paternalismo, como fueron el papado o la monarquía (Romero, 1967, pp. 339, 368). A su vez en esta segunda fase popular, con menor organización que las luchas de sectores mejor posicionados, Romero (1967, p. 371) plantea que eran movimientos más reducidos y con objetivos más acotados: fue el caso de París que luchaba por la ordenación del oficio de los intelectuales. A pesar de este carácter "popular", la huelga no se enfrentó contra un patriciado sino contra el obispo mismo, y en este punto se acercó más a los primeros movimientos "antiseñoriales" (los populares apelaron a una renovación del patriciado para acceder a los cargos de poder). 
Esto lo expresa el juramento al cual se vieron sometidos con el primer acuerdo (en tiempos de Felipe Augusto) que muestra la génesis de su accionar: el sentimiento negativo de rechazo a la injerencia episcopal tomaba valores positivos en la conciencia corporativa y cristalizaba en la institucionalización del grupo (proceso que se dio en las ciudades y en la Universidad de París) (Romero, 1967, pp. 339-41). Fue una lucha originaria, no una renovación, y la última huelga con su gran dispersión fue coronada por la institucionalización plena del oficio y su autonomía corporativa (Gorochov, 2018, p. 101). Como dice Le Goff (1971, p. 89), el siglo XIII fue el siglo de las universidades porque fue el siglo de las corporaciones, es decir, la fase de institucionalización del renacimiento urbano. Contradictoriamente, la universidad comenzó su paralización y decadencia y el ciclo revolucionario inició una nueva fase.

Esta “impureza” del caso parisino también reafirma la cronología que Romero estipula: si la segunda mitad del siglo XIII se caracterizó por la radicalización de los movimientos y la participación de sectores menos enriquecidos, los elementos "mezclados" de las dos oleadas de revueltas encontraron en París un ejemplo de transición. Hay que tener en cuenta que para 1230, las luchas a lo largo de Europa occidental estaban en pleno desarrollo, y a las circunstancias materiales comunes se agregaba la influencia de los líderes que se trasladaron llevando sus experiencias y poniendo en práctica aprendizajes, como muestra el caso de Arnaldo de Brescia -que por cierto, estudió en París- (Astarita, 2016, p. 30). La universidad no solo era parte del movimiento urbano sino que, ya a nivel europeo, fue coronada como tal por el movimiento comunal (Le Goff, 1971, p. 84). La universidad siguió un camino paralelo al que recorrieron las ciudades, en alianza con poderes superiores, por su autonomía interna para gobernar su actividad (Astarita, 2005, p. 6).

La actitud señorial comparte el cuadro general de reacción ante los movimientos comunales: intención de encuadrar las nuevas formas de vida a través de medidas de acción directa que escalaban en importancia, como también utilización de sus funciones particulares (excomunión en el caso del obispo) y de su situación estamental (beneficiar con privilegios a ciertos sectores para dividir la lucha). Esta acción estaba atravesada por la relación con el resto de los poderes, sobre todo con el papado, al cual no se lo puede pensar unilateralmente como aliado de los universitarios en detrimento del poder local, sino que de hecho se acercaba al obispo en tanto ejecutor de su poder, ya que tenía en la universidad un interés particular.

Un último elemento, central en los movimientos comunales, hizo su aparición en la huelga universitaria. Se trata de los agitadores e intelectuales, tanto del movimiento en lucha como de la resistencia: eran expresión de las contradicciones objetivas (como todos los movimientos) pero aportaron una lectura singular de la situación y lograron expresar los intereses del grupo y comunicar los objetivos que elaboraban dirigiendo el movimiento (Astarita, 2016, pp. 24-27). Es decir que hubo una operación intelectual más o menos desarrollada, muchas veces con instancias de elaboración más teórica-como es el caso de los intelectuales, profesionales del pensamiento- pero también experimentalmente en la lucha misma, que permitía a estos sujetos ganar el apoyo del movimiento y construirlo, poniéndose a la cabeza e incidiendo directamente en su dinámica. En la huelga de 1229-1231, los universitarios abandonaron la ciudad solo permaneciendo en general los que no apoyaban la huelga.

El análisis de los sermones de distintos predicadores de la Iglesia permite abordar los objetivos particulares de los agitadores intelectuales en el conflicto y las razones detrás del intento de controlar y usar el oficio intelectual. Fue un oficio clave para la formación de dirigentes eclesiásticos portadores de objetivos esenciales para la institución: la fundamentación del orden feudal y la formación permanente de cuadros consagrados a eliminar cualquier disidencia en tiempos de diversificación social ${ }^{7}$. Tener en cuenta todo esto permite profundizar sobre las formas de lucha y los objetivos de este estamento de la clase dominante para con las nuevas formas de vida urbana que se lanzaron a encuadrar. 


\section{2) La otra prédica: la huelga de la Universidad de París (1229-1231) como "ESCUELA DE GUERRA" DEL INTELECTUAL DEL SISTEMA}

¿Qué dicen los sermones ${ }^{8}$ de miembros de distintos segmentos del estamento eclesiástico sobre la lucha por el control de la corporación y los objetivos que tenía la Iglesia en la Universidad? Ante todo se presentan factores de agitación que no responden únicamente a la oposición episcopado-universidad por el control del oficio, sino que muestran el universo urbano en el cual intervenía la Iglesia como poder señorial para encuadrar la organización corporativa y su forma de vida bajo su dirección, pero también como estamento ideológico de la clase dominante que tenía un interés particular en la universidad e impulsaba un proyecto educativo propio, parte de su programa político (Astarita, 2016, pp. 21-23).

En el período más álgido del conflicto entre universidad y poder episcopal, cuando la huelga fue acompañada por el abandono de la ciudad (1229-31), permanecieron en París sin unirse al movimiento maestros y estudiantes que se oponían a las medidas de fuerza -en general maestros alineados con el poder episcopal-, o aquellos miembros de la corporación que no apostaban por llevar la lucha hasta sus últimas consecuencias, y se convirtieron por consiguiente en el principal objetivo de las predicadores opuestos a la huelga. Dentro de este grupo se encontraban miembros de ambos brazos de la Iglesia que a su vez ocupaban distintas posiciones en la jerarquía eclesiástica, empezando por el obispo de París, Guillermo de Auvergne, junto a un miembro más bajo del clero secular, el maestro en teología Guiardo de Laón, además de dos miembros de las nuevas órdenes mendicantes, el fraile dominico Juan de San Egidio, maestro de medicina y teología y médico de Felipe Augusto, y un bachiller franciscano de nombre desconocido. Todos predicaron en distintos momentos en contra de la lucha y a favor de diversos modelos de universidad subordinados a los intereses eclesiásticos.

Eran intelectuales que se dirigían a un público escolar, cuestión que habilitaba la cuidada elaboración de sus discursos con una abstracción dada por el uso de alegorías a través de los relatos bíblicos. Habían sido formados no solo en teología, lo que se expresa en el contenido de la predicación, sino y sobre todo en las artes liberales, las cuales al estar centradas en la lectura, el comentario y la disputa, los formaron en el uso de la palabra en público y en establecer un armazón lógico-argumental organizado para convencer. Si bien forma y contenido de la predicación no pueden ser escindidos, ya que en su unidad se conseguían los objetivos persuasivos ${ }^{9}$, el discurso tanto en términos formales -la retórica-como lógicos -la dialéctica- estuvo en el centro de la educación medieval ${ }^{10}$ (en el estudio teórico tanto como en su praxis). Siendo un público formado, la retórica hacía a su especificidad en el oficio y mostraba la operación racional meditada detrás de la predicación: se pensaba qué y cómo expresarse de acuerdo al receptor del mensaje, y a través de la palabra se esperaba modificarlo ${ }^{11}$, para predicar un mensaje que fuera comprensible y aprehensible.

El manual del predicador de Thomas de Chobham agrega otro punto que se refleja en los sermones y fue central para la lucha que dio la Iglesia en este conflicto, al afirmar que todo thema de predicación debía tomarse del Antiguo o del Nuevo Testamento, y no de los escritos paganos (Fraboschi, 1991, p. 61). Un punto central de la huelga fue la crítica al abuso en el empleo de los filósofos, tema conocido desde que se prohibieron ciertas lecturas, lo cual no fue aceptado por todos: la predicación del bachiller franciscano utilizó al Filósofo para justificar la fe (y luego del conflicto en la segunda mitad del siglo XIII, la Summa de Tomás de Aquino mostró su apropiación más avanzada, ya en otro contexto). Se recomendaba la cita de autoridad para probar la verdad del argumento pero evitando el detalle para que no pudiera comprobarse (esto variaba de acuerdo al conocimiento de las Escrituras que tenía el público), apuntando a los objetivos mayores constituyentes de la persuasión: la claridad y verosimilitud del mensaje. Toda esta preparación que determinaba la elaboración intelectual y el acto de la predicación estaba atravesada por las aptitudes de índole carismática que el orador tenía e iba desarrollando en tanto agitador en un conflicto particular con relaciones de fuerza singulares. 
Una de las predicaciones claves durante el conflicto fue la del obispo de París, Guillermo de Auvergne, quien no solo reprimió los disturbios sino que también defendió sus prerrogativas episcopales contra la autonomía universitaria, desafiando incluso las amenazas que había recibido del papa Gregorio IX dos años antes (Chartularium, 1991, p. 44). Su crítica se basó en la vida universitaria y en la materia doctrinal, proponiendo un modelo de Iglesia militante donde la enseñanza no tenía autonomía. Recurrió a citas bíblicas y al modelo dualista agustiniano sobre la realidad celestial y terrenal, que debía - para él- ser copiada por la Iglesia $^{12}$. También dictaminó sobre los tipos de conocimiento y la verdad, ya que para esa concepción estudio y tarea religiosa estaban absolutamente imbricadas, y por ende una forma de Iglesia conllevaba una forma de conocer y unos métodos de estudio particulares.

Empezó interpelando al público escolar que lo escuchaba y condenando a los filósofos como lectores erróneos del Libro donde se conocía el orden del cielo. Las tareas de conocer y la de construir la Iglesia se volvían inescindibles, oponiendo la Palabra al conocimiento de los antiguos -que tanto buscaron los intelectuales medievales- con un dejo de nominalismo conservador en la línea agustiniana, donde el sujeto pensante estaba reducido a la tarea de numerar, decir y reproducir el orden del cielo ${ }^{13}$. Luego de exponer la jerarquía celestial, criticó cómo el mundo estaba ordenado contrariamente a como debía ser, acercándose al infierno ${ }^{14}$. La denuncia del desorden universitario y su condena por ser un orden infernal, junto a una salida programática, revela intenciones claras ante un público que lo escuchaba el día de la Vigilia de todos los Santos: hablaba contra la huelga y la universidad creando un estado de ánimo anti-corporativo (Romero, 1967, p. 369). La corrupción de los clérigos que no entendieron la Palabra provenía de sus actos, de su vida de prebendas y riqueza que impedía una correcta lectura, así como de situaciones mundanas y vicios ${ }^{15}$, enfilando hacia la herejía. Frente a esto ponía como modelo la contemplación, contracara de su modelo autoritario, donde se reducía la capacidad intelectiva y de agencia (yendo contra las condiciones de transformación de los universitarios en sujeto político) procurando lograr el mero acatamiento sin injerencia subjetiva propia.

San Agustín y San Bernardo fueron las autoridades a las que recurrió para atacar no solo a los malos estudiantes ${ }^{16}$ sino a las órdenes mendicantes ${ }^{17}$. El obispo representa lo que Romero $(1967$, p. 335) llama una fuerza tradicional, porque si bien se había formado en París y su sermón era el de un intelectual, sus citas y las formas de conocimiento que reivindicaba eran conservadoras, en coincidencia con su proyecto reaccionario ante las nuevas fuerzas sociales en desarrollo ${ }^{18}$. Contrasta con el clérigo franciscano -producto del desarrollo urbano- que logró poder utilizar las innovaciones intelectuales a favor del proyecto eclesiástico, convirtiéndose en su vanguardia (Duby, 1993, p. 141). Por último, Guillermo arremetió contra la universidad como representante de la vida viciada de la ciudad: "cella vinaria claustra debent esse et etiam scholae ubi debet vinum probari [...] caupones tui miscent aquam vino [...] fures sunt. Item proditores sunt" (Episcopi Parisiensis, 1230, p. 76). Más allá que no es casualidad que aparezca nuevamente la taberna como símbolo de la nueva sociabilidad urbana, se destaca que el obispo no solo luchaba por una universidad para la Iglesia (el papa igualmente la defendía aunque deseaba que fuera autónoma), sino que también, en tanto señor feudal, ansiaba subordinarla -junto a la ciudad-a su poder, cuestionado por la huelga ${ }^{19}$.

Unas semanas antes, durante la fiesta de San Francisco, había dado un sermón ante los mismos escolares que permanecieron en París un famoso predicador y maestro en teología, Guiardo de Laon. Con otra ubicación respecto al obispo, como maestro y ex canciller universitario, su sermón no hacía explícita referencia al conflicto, pero sí tomaba posición frente a la lucha contra la tendencia laica en la universidad. En última instancia, de cara al fenómeno urbano que se evidenciaba en la vida de los estudiantes, hacía un llamado a la pobreza y la humildad condenando el lucro, y se dirigía principalmente a los franciscanos para que tomaran la delantera en la tarea que planteaba. Había una clara intención moralizante hacia los clérigos para que se enfilaran en el proyecto de Cristo: "ad destruendum, ad ostendendum et ad referendum" (Guiardi, 1230, p. 110). 
En esta tarea se sirvió de diversos elementos de la realidad que eran conocidos para el público, además de las largas citas de las Escrituras. El día de la fiesta del santo que había sido canonizado apenas cuatro meses atrás, Guiardo recuperó su historia de vida -comparándola con la de San Pablo-para contrastar su origen "erat legatus diaboli" (Guiardi, 1230, p. 108) y la posterior rectificación de su conducta, construyendo así lo central de su mensaje. Llamaba a la tarea de pacificar el mundo y reconciliarse con Dios a través de las armas de la prédica contra el demonio. Los elementos eran conocidos: la vida del predicador de Asís había sido recientemente enaltecida, la entrada de la orden de los Hermanos Menores en París era contemporánea, y la historia de vida arraigaba dentro del sentido de lo posible ya que se asemejaba a la cotidianeidad de cualquier habitante de la ciudad. Su intervención se realizaba, evidentemente, en otro plano que la del obispo: no negó la religiosidad urbana sino que planteó intervenir directamente en ella para dominarla e incitaba a los franciscanos (y a los que no lo eran y estaban escuchando) a que se perfeccionaran en ello. Para Romero (1967) "el fraile mendicante que visitaba casa por casa llegó a ser un eficaz instrumento para la formación de corrientes de opinión" (p. 325). La universidad tuvo, en este caso, un lugar central para la formación de este instrumento ${ }^{20}$.

Por otra parte, la intervención del maestro Juan de San Egidio revela, como la del obispo, un proyecto educativo más específico (y explícito) que el de Guiardo. Pero a diferencia de Guillermo centrado en sus propios intereses como señor feudal local, San Egidio trascendió el conflicto originado por la huelga para plantear un proyecto de universidad integrado al de la Iglesia reformada. Su prédica supera la mera crítica a la vida que llevaban muchos estudiantes: se trataba de una propuesta de universidad al servicio de la formación del clérigo para que pudiera volver a la parroquia armado, condenando a quienes se atrasaban en sus estudios y se dedicaban a estudiar sin un objetivo práctico ${ }^{21}$. Esta crítica también aludía al excesivo número de maestros, crítica que compartían el obispo e Inocencio III $^{22}$. Tomando la vida de Cristo como ejemplo, predicaba la vida a partir de la limosna y reprobaba la fornicación y las prebendas, las cuales atribuía al diablo corrupto que generaba impíos y herejes. Hay una apelación directa a la actividad de los escolares: los interpelaba por la razón de ser de sus estudios, por la forma de dar clases y por la intervención en las disputas. Lejos de una crítica abstracta, situaba su propuesta en las propias tareas concretas del oficio: era un sermón más que verosímil porque se volvía realizable. Por último, condenó a Aristóteles y reivindicó la teología como sabiduría: si la intención era abreviar los estudios, la filosofía no parecía el mejor camino ${ }^{23}$. Su sermón muestra el rol policial que tendrán los dominicos (a quienes el fraile se unió unos meses antes) en la universidad y en la ciudad, regimentando qué, cómo y para qué estudiar, así como contra quién y cómo luchar (Duby, 1993, p. 138).

Aun con estas diferencias que lo separaban del proyecto del obispo para la universidad, Juan de San Egidio mostró su rechazo a la huelga y la autonomía universitaria con su acción: continuó dando clases en la facultad de teología uniendo el ejemplo a la palabra (Fraboschi, 1991, p. 48). Detrás de esta actitud no solo había una intención política, sino que operaban condiciones objetivas porque los religiosos no necesitaban un salario para vivir, como sí lo necesitaban otros maestros, teniendo asegurado el sostenimiento de su posición ideológica y su lucha política en sus condiciones de existencia (Le Goff, 1971, p. 127). Unos meses antes de dar el sermón se había unido a la orden de los dominicos, expresión a través de su biografía del triunfo último de los mendicantes que lograron ingresar a la universidad y dominarla -luego de la larga lucha de la segunda mitad del siglo XIII contra los seculares-, resolviendo la contradicción planteada durante el conflicto de pertenecer a una orden y a una corporación (Le Goff, 1971, p. 134). Su sermón es muestra de esa lucha, y anticipa su resolución.

Un último caso singular de predicador del sistema es el de un bachiller franciscano de nombre desconocido. Su prédica, con menor elaboración intelectual y mayor tono reflexivo, es a la vez la que mejor expresa la nueva religiosidad urbana determinada por la interiorización religiosa ${ }^{24}$. En primer lugar porque lo que estaba haciendo era llamar a reflexionar sobre la situación individual de sus oyentes como clérigos y, en ausencia de todo rastro de agresividad o imposición, se dirigía a sus pares como iguales. No aparecían jerarquías, solo 
la misión trascendental de mostrar el camino recto. De hecho, reivindicó la castidad y la pobreza criticando la soberbia y justificó ese camino con una cita del mismísimo Aristóteles: "paupertas medium erit eundi in paradisum. Et propter hoc Philosophus vocat paupertatem: auream" (Fratris Minoris, 1231, p. 136). Esta apropiación muestra cómo los mendicantes se pusieron a la cabeza de la cruzada contra la forma de vida urbana con las mejores herramientas que encontraron (contradictoriamente, las propias de la sociabilidad en la ciudad), distinto a la actitud "conservadora" del obispo, incidiendo sobre la configuración misma del poder eclesiástico. Su sermón expresa uno de los principales fenómenos que irrumpían con la vida social de la ciudad, la cualidad del trabajo teológico (Astarita, 2015b, p. 131), y con su accionar como intelectual contribuía, en la práctica -de la lucha-, a sistematizarlo, aún sin proponérselo expresamente ${ }^{25}$.

"Sic homo se debet videre in speculo in quo resultat imago; necesse est autem ut se videat in speculo quadruplici scilicet: in speculo conscientiae [...] in speculo scripturae [...] in speculo creaturae [...] in speculo naturae" (Fratris Minoris, 1231, p. 138, 140). Era un fenómeno nuevo que la conciencia y la naturaleza aparecieran a la altura de las Escrituras para ver a Dios, siendo una evidencia de la religiosidad y la mentalidad nueva que trasladó el objeto de fe a un ámbito más lejano dando lugar a nuevos intermediarios entre el hombre y Dios, como la sociedad y la naturaleza (Romero, 1967, p. 514). "La autonomía interior del hombre se hacía más amplia" (Romero, 1967, p. 515), efusión religiosa suscitada por las nuevas formas de vida que, según Romero, las órdenes mendicantes consagraron, privilegiando el servicio de los semejantes como el servicio de Dios. La nueva realidad social que permitía ver al sujeto, a su agencia, se expresaba en este sermón como un llamado a la alegría que debía tener el estudiante que podía intervenir en la sociedad. Lejos de una idea estática y monolítica del estamento eclesiástico y su institución, la intervención de la Iglesia en diversas luchas (y la apropiación diferenciada de los autores antiguos) muestra cómo esta se transformó al calor del desarrollo histórico, muchas veces dirigiéndolo.

Todas estas predicaciones se concentran en uno o dos ejes principales: las tareas de poder que se le presentaban a la Iglesia ante un mundo cambiante y desafiante, y el rol de la educación para alcanzar dicho objetivo político. Sin embargo, la particularidad de cada sermón, que responde a los segmentos estamentales a los que pertenecía cada predicador -y que disputaban entre sí-, así como a los propios artificios de la subjetividad de los intelectuales, abrieron toda una serie de discusiones determinadas por esas condiciones y el público receptor: la vida en la universidad y en la ciudad, las costumbres y la moralidad de los clérigos, las lecturas y los autores aceptados, las distintas concepciones de clérigos y estudiantes, el rol de la teoría (y del dogma) en la formación y concepción del mundo, etc. La jerarquía que tomaron los temas tratados respondía a la singularidad del predicador en el ámbito universitario, y que luchara por imponerse como autoridad se entiende en un contexto de disputa donde el otro (la corporación que rechazaba la subordinación a la Iglesia) aparecía ya no conviviendo sino como negación abierta del modelo defendido por los predicadores.

Un predicador no podía "agitar" una enorme cantidad de ideas, aunque su público se especializara en el pensamiento y se hubiera formado en la oralidad, ya que no eran nociones simples sino que se desarrollaban grandes discusiones de carácter propagandístico que daban cuenta de un programa político-ideológico. En este sentido, el sermón del obispo terminaba siendo no tan elaborado, en términos de la idea-fuerza que transmitía, ya que frente al mensaje represivo y al modelo de universidad que imponía, bastante transparente, aparecían discursos como el del bachiller franciscano o el maestro dominico que leyeron un cambio social sin posibilidad de detener pero sí dominar usando los propios elementos que emanaba la realidad nueva. No era pura virtud individual; se trataba de representantes de órdenes que se abocaron a pensar las formas de combatir prácticas que excedían el control de la Iglesia, y por ende lo que estipulaba como posible, de las cuales ellos eran producto pero que se volcaron a dominar al servicio de la Iglesia ${ }^{26}$.

Se reconocen por lo menos dos perfiles de predicaciones: por un lado el obispo encarnando las fuerzas tradicionales que seguían resistiéndose, por lo menos parcialmente, a la centralización monárquica de la Iglesia como también a las innovaciones que aportaba la ciudad para renovar la forma de dominación desde la función eclesiástica; por el otro, los otros tres predicadores que se apropiaron en mayor o menor medida de 
los cambios sociales, haciendo foco en la nueva religiosidad y las armas que con ella podía desarrollar la Iglesia. Se trataba de una lucha menos frontal que la del obispo pero más elaborada y eficaz, que llamaba a la paz y la negociación a la vez que declaraba una guerra contra los que cuestionaban el poder establecido, porque si bien tenía un objetivo conservador -reproducir la forma de dominación-, esta debía ajustarse a la ampliación de la vida social que a su vez exigía una ampliación de ese control. Aún así, luchaban por objetivos comunes ${ }^{27}$. Las herejías de los siglos XI-XIII eran eclesiológicas, ya que aún llevando el dogma a los límites que permitía el pensamiento religioso - la razón al servicio de la sin-razón-, los límites de lo que la Iglesia definía como hereje eran borrosos, es decir, se adecuaban a la acción de cada situación en que se disputaba su poder.

Los sermones dan cuenta de la predicación de intelectuales del sistema no solo porque se formaron en la universidad y se dedicaron -muchos fuera de ella en el rol religioso- a pensar y enseñar, sino porque lograron formular ideas que mostraban "concretamente el proceso de actos a través de los cuales una voluntad colectiva organizada" (Gramsci, 2013, p. 317) actuaba por y para los objetivos establecidos ${ }^{28}$. La defensa de la teología como saber supremo para garantizar la formación de cuadros militantes de la Iglesia era el proyecto común que atravesaba todos los sermones, aunque se diferenciaban en la forma en que buscaban intervenir en la realidad, de la mejor manera posible y con objetivos comunes diferenciados, muchas veces contradictorios. "El proyecto tiene que ser comprendido por todo elemento activo, de tal modo que vea cuál tiene que ser su tarea en la realización y actuación [...] permite prever sus consecuencias positivas y negativas [...] ofreciendo en suma un campo de organización" (Gramsci, 2013, p. 317). Esta intención estaba detrás de predicaciones no destinadas al público laico en general sino a escolares que se formaban para reproducir esa tarea. Contra "el desarrollo de un pensamiento especulativo lanzado hacia la indagación racional de problemas fundamentales antes vedados" (Romero, 1967, p. 536), la Iglesia desarrolló sus armas, permitiendo afrontar las nuevas exigencias al utilizar los mismos métodos que combatían, como fue el caso que encarnaron las órdenes mendicantes.

Los sermones presentan una característica: hay un uso de leguaje militar que da cuenta de un combate tanto en las ideas como en la acción misma de predicar, y en las intenciones -dominar la ciudad-. La idea de enemigo es la más recurrente, dando cuenta de una lucha, aunque también el obispo (1230, pp. 75, 77) hablaba de guerras y traidores citando al combativo San Bernardo sobre la debilidad de los hombres y la necesidad de la fortaleza en el estudio dirigido a Dios ${ }^{29}$. Esta idea de virilidad también aparece en el bachiller franciscano (1231, pp. 135, 137), quien a pesar de su falta de agresividad exterior en el mensaje, hablaba del combate y de la represión interior de deseos, así como de reprender como predicador a través de la palabra. En el sermón del maestro Guiardo (1230, pp. 109, 111, 113, 115) conviven un llamado a la paz pensado a través de un medio que es el combate: hablaba de los soldados de Dios, de que sus objetivos eran destruir y encaminar, y su arma, la predicación, donde el temor cumplía una función primordial. Juan de San Egidio (1231, pp. 123, 125), por último, también planteaba un modelo universitario que regimente a los falsos profetas, enemigos del modelo de estudiante cristiano. Inclusive un ejemplo en el bando opuesto, el sermón del canciller Felipe (1230, p. 87) ante los escolares que abandonaron París por Orleans, no incitaba a la violencia sino a negociar pero igualmente hablaba de enemigos "brutos" que pisoteaban la libertad. Su eje estaba en la defensa de la medida de fuerza que conllevaba la huelga y el abandono de la ciudad como búsqueda de justicia: "militia et scientia sese concomitantur. Simul veniunt, simul recedunt [...] 'contentio inter magnanimos recepta est'" (Cancellarii Parisiensis, 1230, p. 91, el resaltado es nuestro). El carácter combativo de esta disputa ya se observaba en las disposiciones que escribiera Honorio III en 1219 al referirse a la universidad que deseaba -contra la negligencia del obispo- ampliar el estudio de la teología para ensanchar sus tiendas de campaña, dilatar su campo de acción y rodear la fe católica por una muralla inexpugnable de guerreros que pudiera oponerse a quienes la asaltaran (Fraboschi, 1991, p. 30).

Esta forma que toma la lucha entre universitarios y el poder eclesiástico, que quería controlar la corporación, toma un carácter estrictamente combativo a la luz del lenguaje de los sermones, pero no como simples metáforas de un duelo de ideas propio de la disputatio, sino como un combate abierto que se plasmaba 
en la lucha en el espacio urbano por el control de la vida universitaria, donde la instancia de intelección era clave. Como en cualquier combate, "el fin más inmediato es derrotar al contrario" (Clausewitz, 2014, p. 17), y en este caso la conclusión del conflicto es diferenciado: la corporación logró su autonomía y se cerró el proceso de institucionalización de la universidad, pero viendo el proceso a largo plazo, el papado, fuerza renovadora y reformada, a través de sus brazos armados -las órdenes mendicantes-, logró introducirse en París y dominar la universidad a fines de siglo, como lo expresaba su máximo exponente, el dominico Tomás de Aquino ${ }^{30}$.

Esta lectura procesual permite volver a pensar el caso de París en el marco mayor de las luchas urbanas medievales desde el punto de vista de la Iglesia. La fuerza reformada dentro de esta había comenzado a luchar por su modelo eclesiástico desde hacía por lo menos dos siglos, las escuelas catedralicias se habían desarrollado con el impulso que generaba la necesidad de reprimir las nuevas formas de religiosidad urbana, donde el papel de las ideas y la formación era central. Un punto álgido correspondió a la lucha contra los cátaros y los valdenses en el siglo XII, cuestión que estuvo en la origen del desarrollo de los estudios de teología en París en ese mismo siglo, el cual sentó las bases del posterior desarrollo de los escolares que comenzaron la lucha analizada. Es decir que la Iglesia no comenzó a luchar a partir del conflicto universitario ni mucho menos, pero este parece haber sido un momento clave de su desarrollo en el marco de la nueva institución y de la religiosidad urbana, teniendo en cuenta que las dos órdenes de mendicantes que tuvieron un papel central en el control de las ciudades y sus formas de vida ingresaron en la principal universidad -cuyo eje era la enseñanza de la teología- a partir del conflicto. Una vez adentro fortalecieron las condiciones desde donde se paraban para el combate.

Estas órdenes sí eran nuevas, o por lo menos recientemente creadas a principios de siglo, lo que permite pensar que su intervención en el conflicto en París -como la de la institución toda- fue una lucha preparatoria, aunque no la primera, de puesta a prueba de métodos, de formas de intervención, de corrección de las ideas rectoras y de sujetos concretos, tanto individuales -líderes- como colectivos -órdenes mendicantes-. La lucha de París resultó una verdadera "escuela de guerra" (Lenin, 1973, p. 15) de la Iglesia. Los sermones evidencian, en su diversidad, el enorme proyecto político - no siempre consciente (Faci Lacasta, 2007, p. 79) - que tenía la Iglesia para renovar la dominación feudal en expansión en tanto estamento de la clase dominante, y plantean el panorama de la disputa a su interior. Ciertos eventos posteriores muestran que sacó conclusiones y cambió algunas orientaciones: el papado para formar cuadros que lucharan contra las herejías fundó universidades como Toulouse -de hecho nutrida por la dispersión parisina (Gorochov, 2018, p. 112) - evitando los posibles conflictos de poder a su interior, y refundó la Inquisición a cargo entonces de su brazo dominico, dos eventos que tuvieron lugar mientras acontecía la huelga de la Universidad de París. También a los frailes menores "en 1233 se les encuentra establecidos en todas las ciudades de Francia del norte" (Duby, 1993, p. 141). El proceso parisino sentó entonces un precedente y fue un momento constitutivo de la experiencia de la clase dominante.

\section{3) A MODo DE CONCLUSIón}

Detrás de las luchas de los burgos en el feudalismo operaban las tendencias propias de la dinámica del modo de producción feudal: la lucha por la privatización de la soberanía fragmentada que correspondía con su grupo social (y se expresaba en el espacio, aglutinándose en centros urbanos), por la obtención de la prerrogativa jurídica que los constituyó -donde se obtuvo- como sujetos políticos cualitativamente iguales a los distintos estamentos de la clase dominante feudal, entonces ampliada. Esta perspectiva que habilita pensar la auto-transformación de las formas sociales por el movimiento de sus propias contradicciones, también permite pensar la lucha de los oficios por su autonomía y gobierno propio en el marco de luchas con determinaciones y fines análogos, partes a su vez del colectivo urbano feudal.

Si el estudio de Romero se muestra controvertido en la apropiación del esquema dual que toma de Pirenne, las tesis posteriores que vuelven a considerar al fenómeno económico urbano a su vez reeditan y 
actualizan la potencia del clásico estudio que pone en el centro las nuevas formas de vida urbana y su acción creadora (Astarita, 2015b, pp.XX-XXVI). La imagen dual de la sociedad feudal es superada por una dinámica interrelación donde las ideas de los agitadores, el pensamiento concreto de los intelectuales sobre situaciones particulares y la acción combativa de los grupos sociales no es solo expresión sino que a su vez incide sobre el movimiento estructural dando lugar al creativo cambio histórico.

\section{Documentos}

Fratris minoris. (1231). Sermo cujusdam in fest beatae Agnetis. En Fraboschi, A. A. (1991). Crónica de la Universidad de París y de una buelga y sus motivos (1200-1231) (pp. 132-141). Buenos Aires: Instituto de Estudios Grecolatinos "Prof. F. Novoa".

Cancellarii Parisiensis. (1230). Sermo quod fecit Aurelianis ad scholares de recessu scholarium a Parisiis quem fecit in virgiliam Paschae. En Fraboschi, A. A. (1991). Crónica de la Universidad de Parísy de una huelga y sus motivos (1200-1231), (pp. 82-105). Buenos Aires: Instituto de Estudios Grecolatinos "Prof. F. Novoa".

Magistri Guiardi. (1230). Sermo in fest sancti Francisci. En Fraboschi, A. A. (1991). Crónica de la Universidad de París y de una huelga y sus motivos (1200-1231), (pp. 108-115). Buenos Aires: Instituto de Estudios Grecolatinos "Prof. F. Novoa".

Magistri Johannis de Sancto Aegidio. (1231). Sermo, Dominica post Epiphaniam. En Fraboschi, A. A. (1991). Crónica de la Universidad de París y de una huelga y sus motivos (1200-1231), (pp. 118-129). Buenos Aires: Instituto de Estudios Grecolatinos "Prof. F. Novoa".

Episcopi Parisiensis. (1230). Sermo factus in Virgilia omnium Sanctorum. En Fraboschi, A. A. (1991). Crónica de la Universidad de París y de una buelga y sus motivos (1200-1231), (pp. 70-79). Buenos Aires: Instituto de Estudios Grecolatinos "Prof. F. Novoa".

Abaelardus, P. Historia calamitatum. En Migne, J. P. (1854). Patrologiae Cursus Completus. Series Latina. Paris.

Chartularium Universitatis Parisiensis. En Fraboschi, A. A. (1991). Crónica de la Universidad de París y de una huelga y sus motivos (1200-1231). Buenos Aires: Instituto de Estudios Grecolatinos "Prof. F. Novoa". de Chobham, T. Summa de Arte Praedicatoria. En Fraboschi, A. A. (1991). Crónica de la Universidad de Paris y de una huelga y sus motivos (1200-1231). Buenos Aires: Instituto de Estudios Grecolatinos "Prof. F. Novoa".

de Novigento, G. De Vita Sua. En Migne, J. P. (1854). Patrologiae Cursus Completus. Series Latina. Paris.

\section{REFERENCIAS}

Astarita, C. (2005). El poder político y el desarrollo intelectual en la Edad Media. Actas y comunicaciones del Instituto de Historia Antigua y Medieval, 1. Recuperado de http://www.filo.uba.ar/contenidos/investigacion/institutos /historiaantiguaymedieval/publicaciones.htm

Astarita, C. (2012). Luchas burguesas en el siglo XII. Realidades y proyecciones históricas. Anales de Historia Antigua, Medieval y Moderna, 44. Recuperado de http://www.filo.uba.ar/contenidos/investigacion/institutos/historiaa ntiguaymedieval/index.htm

Astarita, C. (2015a). Origins of medieval craftsmen. In L. Da Graca \& A. Zingarelli, Studies on Pre-Capitalist Modes of Production (pp. 112-140). Leiden-Boston: Brill.

Astarita, C. (2015b). Estudio preliminar. En J.L. Romero, Crisis y orden en el mundo feudoburgués (pp. XIII-XXXI). Buenos Aires: Siglo XXI Editores.

Astarita, C. (2016). Intelectuales orgánicos y agitadores inorgánicos. Siglo XII, España, Francia e Italia. Revista de Historia Social y de las Mentalidades, 20(1), 11-36. Recuperado de http://www.revistas.usach.cl/ojs/index.php /historiasocial/article/download/2548/2334/ 
Baschet, J. (2009). La civilización feudal. Europa del año mil a la colonización de América. México: Fondo de Cultura Económica.

Claramunt, S. (1999). Un grave conflicto en las universidades del siglo XIII: los frailes en los Studia. Anuario de Estudios Medievales, 29(26), 207-218. Recuperado de http://estudiosmedievales.revistas.csic.es/index.php/estudiosmed ievales/article/view/520/531

Clausewitz, C. von. (2014). De la guerra. Madrid: La esfera de los libros.

Duby, G. (1993). La época de las catedrales. Arte y sociedad, 980-1420. Madrid: Cátedra.

Faci Lacasta, J. (2007). Reforma gregoriana, reforma eclesiástica. En G. del Ser Quijano y I. Martin Viso (eds.), Espacios de poder y formas sociales en la Edad Media: estudios dedicados a Ángel Barrios. Salamanca: Universidad de Salamanca.

Fraboschi, A. A. (1991). Crónica de la Universidad de París y de una huelga y sus motivos (1200-1231). Buenos Aires: Instituto de Estudios Grecolatinos "Prof. F. Novoa".

Gorochov, N. (2018). The Great Dispersion of the University of Paris and the Rise of European Universities (1229-1231). CIAN-Revista de Historia de las Universidades, 21(1), 99-119. doi: https://doi.org/10.20318/ci an.2018.4192

Gramsci, A. (2013). Las grandes ideas. En A. Gramsci, Antología (p. 317). Buenos Aires: Siglo XXI Editores.

Le Goff, J. (1971). Los intelectuales de la Edad Media. Buenos Aires: EUDEBA.

Le Goff, J. (1983). Las universidades y los poderes públicos en la Edad Media y el Renacimiento. En Tiempo, trabajo y cultura en el Occidente medieval. 18 ensayos. Madrid: Taurus Ediciones.

Lenin, I. U. (1973). La enfermedad infantil del 'izquierdismo' en el comunismo. En I.U. Lenin, Obras: Tomo XI (pp. 3-43). Moscú: Progreso. Recuperado de https://www.marxists.org/espanol/lenin/obras/oe12/lenin-obrasesco gidas11-12.pdf

Marx, K. (2015). El capital. Buenos Aires: Siglo XXI Editores.

Morsel, J. (2008). La aristocracia medieval. El dominio social en Occidente (siglos V-XV). Valencia: PUV.

Romero, J. L. (1967). La revolución burguesa en el mundo feudal. Buenos Aires: Editorial Sudamericana.

\section{Notas}

1 Este trabajo se originó en las discusiones que se desarrollaron en el seminario "Intelectuales y agitadores en los movimientos sociales de la Edad Media" que dictó el Dr. Carlos Astarita en la Facultad de Filosofía y Letras de la Universidad de Buenos Aires entre agosto y noviembre de 2016. Agradezco los comentarios y aportes del profesor Astarita.

2 "Fue en esa época -hacia el siglo XI- cuando comenzó a operarse esa revolución burguesa [...] cuyo desarrollo se prolonga hasta nuestros días" (Romero, 1967, p. 9).

3 "La ciudad funciona así como un factor de diferenciación social constitutivo de la aristocracia", "las luchas entre señores rurales y urbanos deberían considerarse como luchas internas de la clase dominante" (Morsel, 2008, p. 285), "la aristocracia urbana no tiene el menor interés en arruinar los fundamentos del juego social" (Morsel, 2008, p. 309).

4 "Perveni tandem Parisius, ubi iam maxime disciplina hec florere consueverat" (Abaelardus, 1854, p. 115); "Sed quoniam prosperitas stultos semper inflat et mundana tranquillitas vigorem enervat animi et per carnales illecebras facile resolvit" (Abaelardus, 1854, p. 126); "sed fama tunc maxime universum mundum" (Abaelardus, 1854, p. 163). "Grammaticorum eo tempore paucitas et inscitia. Erat paulo aute id temporis, et adhuc partim sub meo tempore tanta grammaticorum charitas, ut in oppidis pene nullus, in urbibus vix aliquis reperiri potuisset, et quos in veniri contigerat, eorum scientia tenuis erat, nec etiam modernis clericulis vagantibus comparari poterat. Is itaque cui mei operam mater mandare decreverat, addiscere grammaticam grandevus incoeperat, tantoque circam eamdem artes magis rudes exsititit, quanto eam a tenero minus ebiberat. Tantae vero modestiae fuerat, ut quod deficiebat in litteris, suppleret honesto" (de Novigento, 1854, p. 79).

5 Ver Gorochov, 2018.

6 También en Astarita, 2005, p. 4.

7 "Eran simplemente nuevas formas de vida, nuevos sistemas de normas y valores que la Iglesia recogía del seno de una sociedad en cambio [...] multiplicó la prédica, estimuló el formalismo ortodoxo y organizó una rigurosa persecución [...] 
para evitar la crisis de la religiosidad tradicional [...] porque concernía a los fundamentos mismos del orden constituido [...] una vez percibidos los primeros signos del cambio ideológico, lanzó la Iglesia una ofensiva decidida contra el nuevo estilo intelectual que comenzó a predominar, sobre todo, en las universidades" (Romero, 1967, p. 541).

8 Las ediciones de todos los sermones fueron realizadas en traducción paralela latín-castellano por Fraboschi (1991), basándose en la edición de Davy, M. M. (1931). Les sermons universitaires parisiens de 1230-1. Paris: Vrin., la misma que usara Le Goff (1965) en su clásico estudio sobre los intelectuales, lo cual facilitó la aproximación al tema, en conjunto con su estudio introductorio.

9 T. de Chobham decía que la predicación era el anuncio de la palabra divina para la información de la fe y de las costumbres (Fraboschi, 1991, p. 61).

10 También resaltaba la importancia del estilo, como ornamentación de palabras y frases, sin el cual lo que se dijera y cómo se lo ordenaba no tenía sentido (Fraboschi, 1991, p. 64).

11 Para él la retórica era el arte de hablar con propiedad y elegancia para persuadir, y contaba que algunos predicadores antes de llevar adelante el tema principal proponían un tema breve y lo exponían para captar la benevolencia de los oyentes (Fraboschi, 1991, p. 62). El resaltado es nuestro.

12 "In Job, XXXVIII: 'Numquid ordinem caeli nosti et pones rationem ejus in terra?' [...] 'Omnia fac juxta similitudinem tabernaculi quod ostendam tibi"' (Episcopi Parisiensis, 1230, p. 70).

13 "Ille solus hunc ordinem novit, qui numerat multitudinem stellarum, qui dixit, et facta sunt [...] ad hanc sapientiam poenitus defecit presbyterorum intelligentia vel etiam turpius quam elementarius" (Episcopi Parisiensis, 1230, pp. 70-1).

14 "Similiter in caelo litterali est ordo, in inferno autem est confusio" (Episcopi Parisiensis, 1230, p. 72).

15 "Videntes vana quia mundana respiciunt [...] Cum ergo non resiliant, non vident" (Episcopi Parisiensis, 1230, p. 74).

16 "habemus detractores, qui habentes ponunt laqueos et pedicas, ad capiendum viros" (Episcopi Parisiensis, 1230, p. 76).

17 "Item loco monachorum, et claustralium, habemus irregulares et inobedientes in coenobiis" (Episcopi Parisiensis, 1230, p. 76).

18 Romero (1967, p. 462) plantea la correspondencia entre la (in)estabilidad social y la (in)estabilidad en las costumbres y las ideas que se desarrollan en las ciudades.

19 "qui propter quaestum studere volunt [...] qui propter vanitatem aut inanem gloriam student, martyres sunt diaboli, sed qui in Dei gloriam et honorem student, martyres Christi sunt" (Episcopi Parisiensis, 1230, p. 78). El diablo subvertía el orden divino, en Astarita, 2016, p. 14.

20 "fulgura quae ardent et lucent significant praedicatores qui debent ardere praedicando comminationes Domini" (Magistri Guiardi, 1230, p. 110).

21 "mater Domini non permisit eum in scholis nisi per tres dies [...] et in hoc reprehenduntur illi, qui semper morantur in scholis et nullum fructum faciunt" (Magistri Johannis, 1231, p. 127).

22 "nolite plures magistri fieri" (Magistri Johannis, 1231, p. 122).

23 "fons sapientiae verbum Dei. Dicitur: theologia [...] Quand autem tales veniunt ad theologiam, vix possunt separari a scientia sua, sicut patet in quibusdam, qui ab Aristotele non possunt in theologia separari, ponentes ibi aurichalcum pro auro, scilicet philosophicas quaestiones et opiniones" (Magistri Johannis, 1231, p. 126).

24 "lo típico de un individuo que comenzó a considerarse como tal fue, precisamente, considerarse sujeto [...] estos 'bienes interiores' eran las facultades del hombre, las fuerzas que escondía cada individuo en distinta medida, y que podían operar sobre el mundo exterior" (Romero, 1967, p. 452).

25 "no lo saben, pero lo hacen" (Marx, 2015, p. 90).

26 Dice Romero (1967) que la Iglesia "fue sensible al cambio que se operaba en su seno tanto como al que se manifestaba en la sociedad, precisamente porque concernía a los fundamentos del orden constituido" (p. 541).

27 "Francisco, servidor del clero, luchó en defensa de los sacerdotes" (Duby, 1993, p. 135).

28 Si bien no es un tópico que aparezca en los sermones, las imágenes fueron claves en esta tarea. Ver Duby, 1993 , p. 135.

29 Duby (1993) dice que el Cister fue la punta de lanza del combate contra la herejía (p. 122).

30 Juan de San Egidio entró en la orden de los Hermanos Predicadores en 1230 durante el conflicto, y así los dominicos obtuvieron su segunda cátedra en la facultad de teología (Fraboschi, 1991, p. 116). Los franciscanos obtienen su primera cátedra con Alejandro de Hales en 1235-36 (Fraboschi, 1991, p. 130). 